\title{
Efeitos da disposição de lodo de estações de tratamento de efluentes (ETE) de indústria alimentícia no solo: estudo de caso
}

\author{
Effects of disposal of a food industry \\ wastewater treatment plant sludge on soil: case study
}

Ana Carolina Amaral Pereira', Marcelo Loureiro Garcia²

口-

\begin{abstract}
RESUMO
O lodo proveniente de estações de tratamento de efluentes é rico em nutrientes e contém alto teor de matéria orgânica, podendo desempenhar importante papel no condicionamento do solo e na produção agrícola. Entretanto, é importante que sua utilização no solo seja feita de maneira controlada devido à possibilidade da presença de constituintes poluentes. $\mathrm{O}$ presente trabalho objetivou analisar os efeitos da aplicação em escala real de lodo de estação de tratamento de efluentes em uma área de Latossolo cultivado com eucalipto (Eucalyptus sp.), assim como avaliar a compatibilidade do lodo com a disposição no solo. Os resultados indicam que o lodo utilizado apresenta características adequadas à aplicação no solo de acordo com a Resolução CONAMA no 375/2006 em relação aos constituintes inorgânicos. Não houve diferença entre as áreas receptoras de lodo e testemunha quanto às substâncias orgânicas potencialmente tóxicas. Foi verificada uma tendência de pequeno aumento da concentração dos constituintes inorgânicos (Al, Ba, B, Co, Cu, Fe, Mn, Ni, Zn), o que não foi confirmado estatisticamente. A aplicação de lodo contribuiu para o aumento da fertilidade do solo das glebas receptoras, indicado pelo aumento da saturação por bases, soma de bases, CTC e matéria orgânica, além da redução do alumínio trocável e da saturação por alumínio.
\end{abstract}

Palavras-chave: disposição de lodo no solo; lodo de ETE; solo. 口

\begin{abstract}
Sludge from wastewater treatment plants usually contains high levels of organic matter and nutrients, and therefore it can be used as fertilizer and soil conditioner. However, its disposal on the soil has to be properly managed because it can contain contaminants. The aim of this work was to study the effects of food industry sludge disposal on the soil, as well as to assess the sludge application viability. The results show that the sludge characteristics are adequate for its application on latosol according to Brazilian federal regulation (Resolução CONAMA no 375/2006). There was no statistically significant difference for toxic organic substances between the amended and unamended soil treatments. There was a small concentration increase of inorganic compounds (Al, Ba, B, Co, Cu, Fe, Mn, Ni, Zn) in the soil area with sludge but it was not statistically confirmed. Soil fertility, sum of bases, cation exchange capacity, and organic matter values increased with sludge application, and exchangeable Al and Al saturation values decreased.
\end{abstract}

Keywords: sludge application on soil; wastewater sludge; soil.

\section{INTRODUÇÃO}

As estações de tratamento de efluentes (ETE) têm por objetivo a remoção dos poluentes, nutrientes e matéria orgânica presentes nas águas residuárias antes que retornem ao meio ambiente. O lodo produzido em uma ETE corresponde a cerca de 1 a $2 \%$ do volume do efluente tratado, entretanto o tratamento e a disposição final desse resíduo representam de 30 a 50\% do custo operacional da estação (SANEPAR, 1999). As características do lodo gerado em ETEs são muito variáveis. Lodos de esgoto sanitário podem apresentar alta concentração de patógenos
(SILVA et al., 2001), assim como cargas altas de contaminantes químicos provenientes de produtos domésticos de limpeza, cosméticos, higiene pessoal e remédios (SAITO, 2007; SMITH, 2009). Similarmente ao resíduo doméstico, a natureza da atividade industrial, como o tipo de processo produtivo e insumos utilizados, determina a composição do lodo. Asik et al. (2015) verificaram maiores concentrações de zinco, chumbo e níquel totais em lodo de efluente sanitário municipal do que de duas indústrias alimentícias (fabricação de fermento e comida enlatada) e de um distrito industrial. Em lodo de abatedouro, mesmo $\square$

"Instituto de Geociências e Ciências Exatas, Programa de Pós-Graduação em Geociências e Meio Ambiente, Universidade Estadual Paulista “Júlio de Mesquita Filho” (UNESP) Rio Claro (SP), Brasil.

IInstituto de Geociências e Ciências Exatas, Departamento de Petrologia e Metalogenia, UNESP - Rio Claro (SP). Brasil.

Endereço para correspondência: Marcelo Loureiro Garcia - Avenida 24-A, 1515 - Bela Vista - 13506-900 - Rio Claro (SP), Brasil - E-mail: mlgarcia@rc.unesp.br

Recebido: 06/08/15 - Aceito: 12/07/16 - Reg. ABES: 152945 
sem a contribuição de esgoto sanitário, são verificados altos níveis de contaminantes microbiológicos (MÉNDEZ-CONTRERAS et al., 2009). Lodos com alta concentração de metais estão relacionados principalmente com galvanoplastia, curtumes, indústrias farmacêuticas e de formulação de compostos orgânicos, fundições, lavanderias, indústrias de petróleo, de corantes e pigmentos (SILVA et al., 2001).

A partir do diagnóstico do lodo, sua disposição no solo torna-se interessante dentre outras alternativas de manejo do resíduo, como a disposição em aterros sanitários, a incineração e a utilização na recuperação de áreas degradadas, e na produção de substratos (LARA; ANDREOLI; PEGORINI, 2001). Em alguns países desenvolvidos, a aplicação de lodo no solo ocorre há mais de 20 anos - em escala operacional com a destinação de grande parte do lodo gerado para plantações florestais (LIRA; GUEDES; SCHALCH, 2008) - e esta prática é mais recente no Brasil (SAITO, 2007). A aplicação de lodo em culturas de eucalipto pode aumentar a produção de matéria seca (LIRA; GUEDES; SCHALCH, 2008) e volume de madeira (SILVA et al., 2008). Foi verificado também aumento da biomassa de azevém e tomate (MINGORANCE et al., 2014), matéria seca do milho e do feijoeiro (NASCIMENTO et al., 2004), aumento de produtividade e redução do tempo de colheita para o chuchu (MÉNDEZ-CONTRERAS et al., 2009), e ainda incremento na altura e produção de biomassa de mudas nativas brasileiras (PAIVA et al., 2009).

A aplicação de lodo pode também melhorar a qualidade do solo, com aumento dos teores de matéria orgânica, nitrogênio, magnésio e potássio (NASCIMENTO et al., 2004; UNAL \& KATKAT, 2009); de fósforo, cálcio e capacidade de troca catiônica (CTC) (NASCIMENTO et al., 2004); da condutividade elétrica, do carbono orgânico total e da atividade microbiana (MINGORANCE et al., 2014); e do fósforo disponível e da condutividade elétrica (ASIK et al., 2015; UNAL \& KATKAT, 2009). Apesar dos benefícios que a aplicação do lodo pode proporcionar, alguns componentes indesejáveis dos efluentes podem se concentrar no lodo, tais como metais pesados, poluentes orgânicos e microrganismos patogênicos (SILVA et al., 2001). A aplicação do lodo pode causar acúmulo de metais no solo (ASIK et al., 2015; SILVA et al., 2006) e em plantas de milho (SILVA et al., 2006), além de apresentar risco de contaminação das águas subterrâneas com nitrato (DYNIA; BOEIRA; SOUZA, 2006; HARRISON et al., 1994). Dessa forma, o objetivo do presente trabalho foi analisar os efeitos da disposição de lodo de ETE de uma indústria do ramo alimentício no solo em escala real.

\section{METODOLOGIA}

O estudo de caso se baseou nos dados e resultados laboratoriais obtidos pela indústria responsável pela disposição do lodo no solo, por meio de monitoramento ambiental periódico entre os anos de 2012 e 2013.
O lodo foi gerado na ETE localizada em uma indústria do ramo alimentício de transformação de produtos agrícolas (frutas e legumes), localizada na região metropolitana de Goiânia (Goiânia). A ETE é constituída de tratamento primário - peneira rotativa e flotador - $\mathrm{e}$ secundário - lodos ativados - , e apresenta vazão média mensal de $3.607 \mathrm{~m}^{3}, 3$ a $4 \%$ da qual é constituída por efluentes sanitários e o restante por efluentes industriais, provenientes do processo produtivo. O lodo que foi aplicado no solo era uma mistura de lodo primário e lodo secundário, e a quantidade média gerada por mês pela ETE é de 437,5 toneladas, em base seca. Antes da aplicação no solo, o lodo foi desaguado em centrífuga até atingir umidade aproximada de $70 \%$ e recebeu a adição de cal em quantidade suficiente para elevação do $\mathrm{pH}$ do resíduo a 12. O lodo foi aplicado superficialmente no solo nas entrelinhas dos eucaliptos (nas faixas adubadas com lodo) e posteriormente incorporado ao solo.

A área de disposição de lodo consiste em uma fazenda de plantio comercial de eucalipto. A área agrícola onde foi realizado o trabalho é constituída por um latossolo vermelho de textura argilosa, na região metropolitana de Goiânia (SOUZA, 2010). Foram utilizadas cinco glebas de cultura de eucalipto, que totalizam 53,2 hectares. As glebas 1, 2 , 3 e 4, com 39,9 hectares no total, foram utilizadas durante dois anos e meio para aplicação do lodo, e uma área de 13,3 hectares, denominada gleba testemunha, manteve-se sem aplicação.

A aplicação ocorreu em um período total de cinco semestres. A taxa de aplicação em base seca por gleba e por período é apresentada na Tabela 1 . As coletas de lodo e solo para análise foram realizadas no período correspondente aos semestres $3,4 \mathrm{e} 5$. As amostras foram coletadas e analisadas por laboratório contratado pela indústria responsável pela aplicação do lodo.

Uma amostra simples de lodo foi coletada em cada um dos semestres avaliados (semestres 3, 4 e 5). Foram analisados os parâmetros de macro e micronutrientes, constituintes inorgânicos e substâncias orgânicas potencialmente tóxicas. Os metais foram determinados por espectrometria de emissão óptica, pelo método USEPA 6010C (USEPA, 2007a), com prévia digestão ácida pelo método USEPA 3051 (USEPA, 2007b), o mercúrio pelo método USEPA 245.7 (USEPA, 2005), dioxinas e furanos por USEPA 1613 (USEPA, 1994), pH pelo método 9045 (USEPA, 2004), compostos orgânicos voláteis conforme método 8260C (USEPA, 1996), compostos orgânicos

\begin{tabular}{|c|c|c|c|c|}
\hline Gleba & $\begin{array}{l}\text { Área } \\
\text { (ha) }\end{array}$ & Lote de lodo & $\begin{array}{l}\text { Quantidade } \\
\text { aplicada (t) }\end{array}$ & $\begin{array}{c}\text { Taxa de aplicação } \\
\left.\text { (t.ha }{ }^{-1}\right)\end{array}$ \\
\hline Gleba 1 & 7,4 & Semestres 3 e 4 & 638,0 & 86,2 \\
\hline \multirow{2}{*}{ Gleba 2} & \multirow{2}{*}{16,6} & Semestres 1 e 2 & 2449,4 & 147,5 \\
\hline & & Semestre 5 & 439,2 & 26,5 \\
\hline Gleba 3 & 8,5 & Semestres 1 e 2 & 1254,2 & 147,5 \\
\hline Gleba 4 & 7,4 & Semestres 1 e 2 & 1091,9 & 147,5 \\
\hline
\end{tabular}


semivoláteis conforme método USEPA 8270D (USEPA, 2007c), e PCBs e toxafeno pelo método USEPA 505 (USEPA, 1989).

Uma amostra de solo composta por cinco a dez subamostras foi coletada em cada gleba e em cada período analisado (semestres 3, 4, e 5). As subamostras foram coletadas em profundidade de $0-20 \mathrm{~cm}$, nas entrelinhas dos eucaliptos, por toda área da gleba, em pontos aleatórios, $\mathrm{e}$ colocadas em recipiente inerte e homogeneizadas. Deste material, foram coletadas as amostras compostas para envio ao laboratório. As amostras foram analisadas quanto aos componentes inorgânicos por espectrometria de emissão óptica pelo método USEPA 6010C (USEPA, 2007a) com prévia digestão ácida pelo método USEPA 3051 (USEPA, 2007b), fertilidade (RAIJ et al., 2001) e substâncias orgânicas potencialmente tóxicas (USEPA, 1989, 1994, 1996, 2005, 2007a).

Para a verificação da significância da diferença entre os resultados laboratoriais das amostras de solo das glebas testemunha e receptoras de lodo, foram realizados testes de hipótese $t$ de Student, considerando o nível de confiança de 95\%, utilizando-se para tal o software BioEstat 5.3.

\section{RESULTADOS E DISCUSSÃO}

\section{Características do lodo}

De acordo com os resultados obtidos (Tabela 2), as características do lodo aplicado quanto aos parâmetros de constituintes inorgânicos atendem à Resolução CONAMA no 375/2006 (BRASIL, 2006).

Os resultados dos parâmetros cádmio, chumbo, cobre, níquel e zinco se mostraram menores do que os verificados na literatura para lodos originários da ETE municipal de Barueri (BETTIOL \& CAMARGO, 2006; LIRA; GUEDES; SCHALCH, 2008; PAIVA et al., 2009; SILVA et al.,

Tabela2- Resultados da caracterização de constituintes inorgânicos no lodo.

\begin{tabular}{|c|c|c|c|c|c|}
\hline \multirow[b]{2}{*}{ Parâmetro } & \multirow[b]{2}{*}{ Unidade } & \multicolumn{3}{|c|}{ Resultados analíticos } & \multirow{2}{*}{$\begin{array}{c}\text { Limite } \\
\text { máximo } \\
\text { Resolução } \\
\text { CONAMA } \\
\text { n' 375/06 }\end{array}$} \\
\hline & & Semestre 3 & Semestre 4 & Semestre 5 & \\
\hline Arsênio & $\mathrm{mg} \cdot \mathrm{kg}^{-1}$ & 2 & $<1$ & $<1$ & 41 \\
\hline Bário & $\mathrm{mg} \cdot \mathrm{kg}^{-1}$ & 170 & 129 & 93 & 1300 \\
\hline Cádmio & $\mathrm{mg} \cdot \mathrm{kg}^{-1}$ & $<0,098$ & $<0,1$ & $<0,1$ & 39 \\
\hline Chumbo & mg.kg-1 & 6,9 & 5,8 & $<1$ & 300 \\
\hline Cobre & $\mathrm{mg} \cdot \mathrm{kg}^{-1}$ & 69 & 87 & 113 & 1500 \\
\hline Mercúrio & $\mathrm{mg} \cdot \mathrm{kg}^{-1}$ & $<0,049$ & $<0,05$ & 0,21 & 17 \\
\hline Molibdênio & mg.kg-1 & $<1$ & $<1$ & $<1$ & 50 \\
\hline Níquel & mg.kg-1 & 18 & 19 & 25 & 420 \\
\hline Selênio & mg.kg-1 & $<1$ & $<1$ & $<1$ & 100 \\
\hline Zinco & $\mathrm{mg} \cdot \mathrm{kg}^{-1}$ & 169 & 145 & 107 & 2800 \\
\hline
\end{tabular}

Nota: Os valores antecedidos pelo sinal de "menor que" (<) indicam que a quantidade da substância não alcançou o limite de quantificação da amostra.
2008) e da ETE municipal de Franca (BETTIOL \& CAMARGO, 2006). Ainda, vale destacar que os resultados desses constituintes do lodo da ETE de Barueri, que trata esgotos domésticos e industriais, são superiores aos do lodo da ETE de Franca, a qual trata apenas esgotos domésticos.

As características do lodo estão diretamente relacionadas com o tipo de efluente tratado que o originou (SANEPAR, 1999). Uma vez que o efluente do presente estudo provém da indústria alimentícia, a qual não se utiliza de insumos que contenham concentrações altas desses constituintes inorgânicos, é esperado que o lodo gerado apresente baixos teores de tais substâncias, conforme constatado nos resultados.

De acordo com as análises laboratoriais (Tabela 3), o lodo estudado apresenta em sua composição os macronutrientes carbono, nitrogênio, potássio, cálcio, fósforo, magnésio e enxofre, que são necessários ao desenvolvimento das plantas. A concentração das substâncias analisadas variou entre os monitoramentos, possivelmente devido à alteração no processo produtivo, oscilação da vazão e das características do efluente tratado, e também por eventuais alterações na operação da estação de tratamento.

Os resultados deste trabalho são similares aos relatados por Lira, Guedes e Schalch (2008) e por Silva et al. (2008), obtidos de lodo de efluente sanitário e industrial da ETE do município de Barueri, com relação aos parâmetros fósforo, potássio, magnésio e sódio. Já quanto ao parâmetro cálcio, Lira, Guedes e Schalch (2008) obtiveram resultados

Tabela 3 - Resultados da caracterização dos macro e micronutrientes do lodo.

\begin{tabular}{|c|c|c|c|c|}
\hline \multirow{2}{*}{ Parâmetro } & \multirow{2}{*}{ Unidade } & \multicolumn{3}{|c|}{ Resultados analíticos } \\
\hline & & Semestre 3 & Semestre 4 & Semestre 5 \\
\hline Cálcio & mg.kg-1 & 10916 & 6632 & 3794 \\
\hline $\begin{array}{l}\text { Carbono } \\
\text { orgânico total }\end{array}$ & $\% \mathrm{p} / \mathrm{p}$ & 26 & 5,7 & 6,5 \\
\hline Enxofre & mg.kg-1 & $<1116$ & $<1042$ & $<5002$ \\
\hline Fósforo & mg.kg-1 & 3273 & 4876 & 15250 \\
\hline Magnésio & mg.kg-1 & 5544 & 2657 & 2716 \\
\hline $\begin{array}{l}\text { Nitrato } \\
(\text { como N) }\end{array}$ & mg.kg-1 & $<3$ & $<4,9$ & $<4,1$ \\
\hline $\begin{array}{l}\text { Nitrito } \\
\text { (como N) }\end{array}$ & mg.kg-1 & $<0,6$ & $<1$ & $<0,8$ \\
\hline $\begin{array}{l}\text { Nitrogênio } \\
\text { Amoniacal }\end{array}$ & mg.kg-1 & 156 & 686 & 1115 \\
\hline $\begin{array}{l}\text { Nitrogênio } \\
\text { total Kjeldahl }\end{array}$ & mg.kg-1 & 1498 & 42860 & 28128 \\
\hline $\begin{array}{l}\text { pH (suspensão } \\
\text { a } 5 \% \text { ) }\end{array}$ & -- & 6,7 & 5,6 & 7,4 \\
\hline Potássio & mg.kg-1 & 7480 & 4469 & 8606 \\
\hline Sódio & mg.kg-1 & 2035 & 2136 & 816 \\
\hline Umidade & $\%$ & 67,4 & 80,2 & 76,2 \\
\hline
\end{tabular}

Nota: Os valores antecedidos pelo sinal de "menor que" (<) indicam que a quantidade da substância não alcançou o limite de quantificação da amostra. ---Não se aplica. 
uma ordem de grandeza acima dos obtidos neste estudo. Os trabalhos de Nascimento et al. (2004), com o lodo da ETE Mangueira - localizada em Recife -, Paiva et al. (2009) e Silva et al. (2008), ambos em relação ao lodo da ETE de Barueri, corroboram os resultados obtidos para o parâmetro nitrogênio Kjeldahl. Nicolás et al. (2014) indicaram o resultado de $7,8.10^{4} \mathrm{mg} \cdot \mathrm{kg}^{-1}$ para esse parâmetro no lodo de esgoto e $3,0.10^{4} \mathrm{mg} \cdot \mathrm{kg}^{-1}$ para o mesmo lodo após processo de compostagem. As características do lodo são muito variáveis, pois dependem diretamente das características do efluente tratado, do tipo de tratamento e da operação da ETE. Assim, é esperado que haja diferença entre os resultados de caracterização de lodos de diferentes ETEs. As características do efluente tratado também variam ao longo do tempo, o que pode explicar a variação mais expressiva em alguns parâmetros do lodo analisado, como carbono orgânico total, fósforo, nitrogênio amoniacal e Kjeldahl, e sódio.

Os grupos de parâmetros referentes aos fenóis não clorados, hidrocarbonetos aromáticos policíclicos, bifenilas policloradas (PCB), poluentes orgânicos persistentes, benzenos clorados, ésteres de ftalatos e fenóis clorados apresentaram todos os resultados abaixo do limite de quantificação da amostra em todos os semestres estudados. As exceções foram a amostra do semestre 4, que apresentou $8,910 \mathrm{mg}^{\mathrm{kg}} \mathrm{kg}^{-1}$ de cresóis totais e $0,841 \mathrm{mg} \cdot \mathrm{kg}^{-1}$ de naftaleno, e o lodo amostrado no semestre 5 apresentou $0,086 \mathrm{mg} \cdot \mathrm{kg}^{-1}$ de fenantreno e $0,138 \mathrm{mg} \cdot \mathrm{kg}^{-1}$ de naftaleno. Quanto aos parâmetros de dioxinas e furanos, o equivalente tóxico das amostras de lodo analisadas não superou 31,4 ng. $\mathrm{kg}^{-1}$.

\section{Fertilidade do solo}

Os valores de médias e medianas do solo na profundidade $0-20 \mathrm{~cm}$ da gleba testemunha e glebas receptoras, assim como o valor $\mathrm{p}$ do teste $t$ são apresentados na Tabela 4 . Valores menores que 0,05 para o valor $\mathrm{p}$ foram considerados indicação de diferença significativa entre as médias.

Apesar de a média e mediana dos resultados de $\mathrm{H}+\mathrm{Al}$, condutividade elétrica, $\mathrm{pH}$ e sódio trocável das glebas receptoras serem um pouco maiores que da gleba testemunha, essa tendência não foi confirmada estatisticamente. Após aplicação de lodo, Nascimento et al. (2004) verificaram aumento do sódio trocável e redução do pH no solo, Harrison et al. (1994) também verificaram redução do pH. Já Baghina et al. (2014) e Mingorance et al. (2014) verificaram aumento do $\mathrm{pH}$, e os primeiros ainda verificaram aumento da condutividade elétrica.

A média dos resultados obtidos quanto ao parâmetro matéria orgânica da gleba testemunha é $30 \mathrm{~g} \cdot \mathrm{dm}^{-3}$, enquanto das demais glebas é de $38 \mathrm{~g} \cdot \mathrm{dm}^{-3}$, sendo estatisticamente diferentes $(\mathrm{p} \leq 0,05)$.

Quanto ao parâmetro cálcio, na profundidade de $0-20 \mathrm{~cm}$, as glebas que receberam lodo apresentaram valores superiores aos da gleba testemunha (não confirmado pela estatística), o que está condizente com o verificado por Nascimento et al. (2004) e Harrison et al. (1994). As glebas receptoras apresentaram mediana de $12 \mathrm{mmol} \cdot \mathrm{dm}^{-3}$, contra $5 \mathrm{mmol} \cdot \mathrm{dm}^{-3}$ da gleba testemunha.
Foi verificada diferença estatisticamente significativa entre o solo que recebeu lodo e o que não recebeu quanto ao parâmetro soma de bases (Figura 1), apesar de isso não ter ocorrido individualmente para o cálcio, magnésio e potássio. Isso indica que há uma tendência de aumento das bases no solo receptor que pode não ter aparecido nos parâmetros individuais devido ao número reduzido de dados. O parâmetro alumínio trocável resultou significativamente menor no solo receptor de lodo em relação ao solo testemunha.

A média da saturação por bases na gleba testemunha, de $21 \%$, é significativamente menor que a média nas glebas receptoras, de $32 \%$, e a saturação por alumínio na gleba testemunha (26\%) é significativamente maior que nas glebas receptoras (11\%) (Figura 2.).

A CTC efetiva regional apresenta valores muito baixos, sendo a mediana igual a $11 \mathrm{mmol}_{\mathrm{c}} \cdot \mathrm{dm}^{-3}$. Isso indica alto grau de intemperização dos solos com predominância de argilas de baixa atividade, assim como o alto potencial de lixiviação de cátions (LOPES, 1984). Os valores das glebas receptoras (mediana igual a $23 \mathrm{mmol} \cdot \mathrm{dm}^{-3}$ ) são significativamente maiores $(\mathrm{p} \leq 0,05)$ que os verificados na gleba testemunha (mediana igual a $17 \mathrm{mmol} \cdot \mathrm{dm}^{-3}$ ), o que também ocorre com a CTC potencial.

Tabela 4 - Média e mediana dos resultados de fertilidade no solo, na profundidade $0-20 \mathrm{~cm}$ e valor $\mathrm{p}$ do teste $t$ entre solo receptor e solo testemunha.

\begin{tabular}{|c|c|c|c|c|c|c|}
\hline \multirow[t]{2}{*}{ Parâmetro } & \multirow[t]{2}{*}{ Unidade } & \multicolumn{2}{|c|}{ Testemunha } & \multicolumn{2}{|c|}{$\begin{array}{l}\text { Glebas } \\
\text { receptoras }\end{array}$} & \multirow{2}{*}{$\begin{array}{l}\text { Valor } \\
\mathrm{p}\end{array}$} \\
\hline & & Média & Mediana & Média & Mediana & \\
\hline $\mathrm{Al}$ & $\mathrm{mmol}_{\mathrm{c}} \mathrm{dm}^{-3}$ & 4 & 3 & 2 & 3 & 0,03 \\
\hline Cálcio & $\mathrm{mmol}_{c^{\prime}} \mathrm{dm}^{-3}$ & 5 & 5 & 14 & 12 & 0,07 \\
\hline $\begin{array}{l}\text { Condutividade } \\
\text { elétrica }\end{array}$ & $\mathrm{dS} \cdot \mathrm{m}^{-1}$ & 0,09 & 0,07 & 0,15 & 0,18 & 0,18 \\
\hline $\mathrm{CTC}_{\mathrm{pH} 7}$ & $\mathrm{mmol}_{c^{-}} \mathrm{dm}^{-3}$ & 57 & 56 & 70 & 73 & 0,01 \\
\hline CTC $_{\text {efetiva }}$ & $\mathrm{mmol}_{c^{\prime}} \mathrm{dm}^{-3}$ & 16 & 17 & 25 & 23 & 0,03 \\
\hline Fósforo resina & $\mathrm{mg} \cdot \mathrm{dm}^{3}$ & 5 & 4 & 20 & 13 & 0,12 \\
\hline $\mathrm{H}+\mathrm{Al}$ & $\mathrm{mmol}_{c^{\prime}} \cdot \mathrm{dm}^{-3}$ & 44 & 44 & 47 & 47 & 0,25 \\
\hline Magnésio & $\mathrm{mmol}_{\mathrm{C}} \cdot \mathrm{dm}^{-3}$ & 3 & 3 & 5 & 4 & 0,10 \\
\hline $\begin{array}{l}\text { Matéria } \\
\text { orgânica }\end{array}$ & g.dm ${ }^{-3}$ & 30 & 30 & 38 & 37 & 0,01 \\
\hline $\mathrm{pH}$ & --- & 4,4 & 4,4 & 4,6 & 4,6 & 0,08 \\
\hline Potássio & $\mathrm{mmol}_{\mathrm{c}^{\prime}} \mathrm{dm}^{-3}$ & 0,5 & 0,5 & 2.5 & 2,0 & 0,09 \\
\hline Saturação Al & $\mathrm{m} \%$ & 26 & 25 & 11 & 10 & 0,002 \\
\hline $\begin{array}{l}\text { Saturação de } \\
\text { bases }\end{array}$ & $\vee \%$ & 21 & 23 & 32 & 32 & 0,04 \\
\hline Sódio trocável & $\mathrm{mmol}_{c} \cdot \mathrm{dm}^{-3}$ & 0,21 & 0,22 & 0,24 & 0,24 & 0,29 \\
\hline $\begin{array}{l}\text { Soma de } \\
\text { bases }\end{array}$ & $\mathrm{mmol}_{\mathrm{C}} \cdot \mathrm{dm}^{-3}$ & 12 & 13 & 23 & 20 & 0,02 \\
\hline
\end{tabular}

-- Não se aplica. No semestre 3, a gleba 1 ainda não havia recebido nenhum lote de lodo quando o solo foi amostrado, portanto os resultados foram contabilizados na coluna "testemunha" 
A CTC pode ser definida como a capacidade de um solo reter cátions, e está diretamente relacionada à quantidade de cargas negativas que os coloides do solo apresentam. Latossolos sob cerrado têm baixa CTC apesar dos altos teores de argila, uma vez que essas argilas são predominantemente de baixa atividade (LOPES \& GUILHERME, 2004). A adição de matéria orgânica por meio da aplicação do lodo no solo pode ter contribuído para o aumento da CTC nas glebas receptoras.

A fertilidade do solo é inferida principalmente pelos parâmetros soma de bases, saturação por bases, CTC e saturação por alumínio. A fertilidade depende de vários fatores, sendo os principais o tipo da rocha de origem, idade e condições de intemperismo. Solos “jovens" tendem a ser mais férteis, enquanto em solos mais "velhos" e intemperizados - como o latossolo — os elementos que contribuem para a fertilidade, como cálcio e magnésio, são lixiviados do sistema, resultando em solos menos férteis (CORREIA; REATTO; SPERA, 2004). Este fato condiz com os resultados obtidos por Lopes (1984), o qual identificou solos pouco férteis na região de Goiás.

A saturação por bases, soma de bases e CTC são significativamente maiores nas glebas receptoras de lodo, enquanto o alumínio trocável e a saturação por alumínio são menores $(\mathrm{p} \leq 0,05)$, o que indica maior fertilidade nas glebas receptoras de lodo do que na gleba testemunha. Os resultados são corroborados por Nascimento et al. (2004) que também observaram aumento dos teores de cálcio, magnésio, potássio e CTC em solos tratados com diferentes doses de lodo de esgoto. Harrison et al. (1994) também verificaram, mesmo após 15 anos da

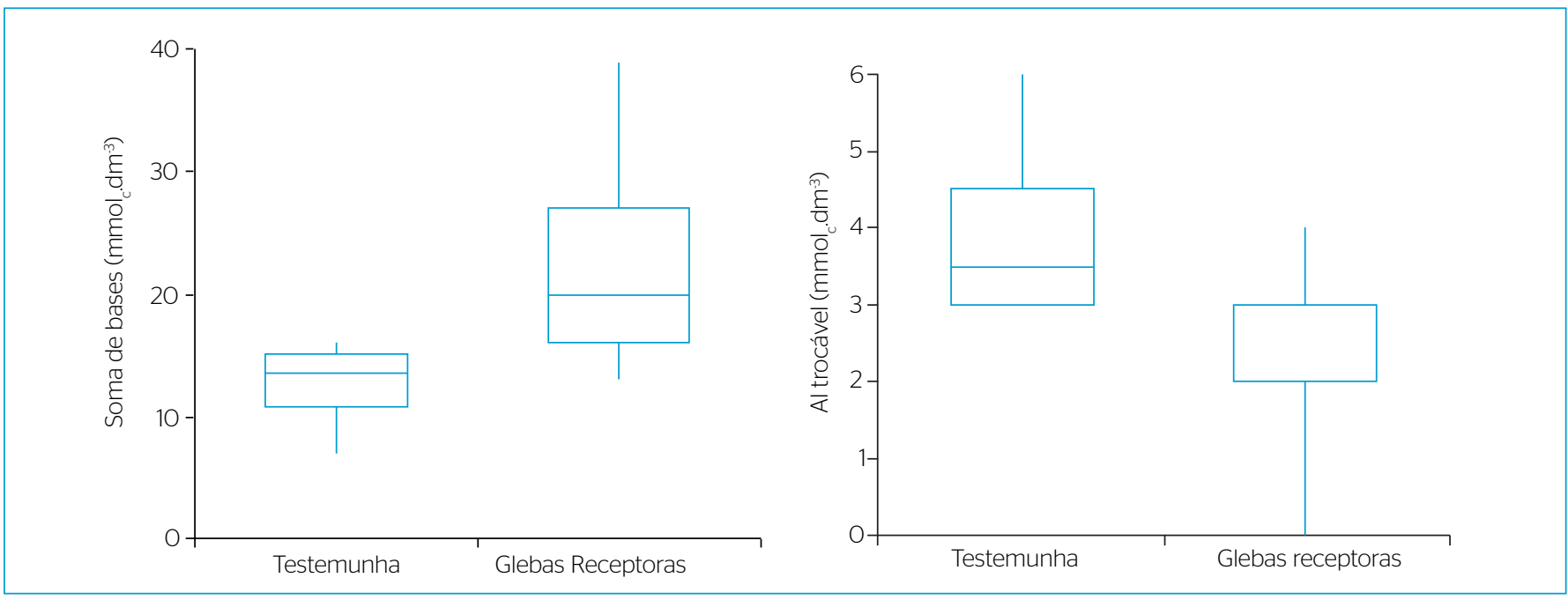

Figura 1 - Box-plot apresentando a mediana, os quartis e o maior e menor valor referente às análises de solo quanto aos parâmetros "soma de bases" e "alumínio trocável" para a gleba testemunha e glebas receptoras de lodo.
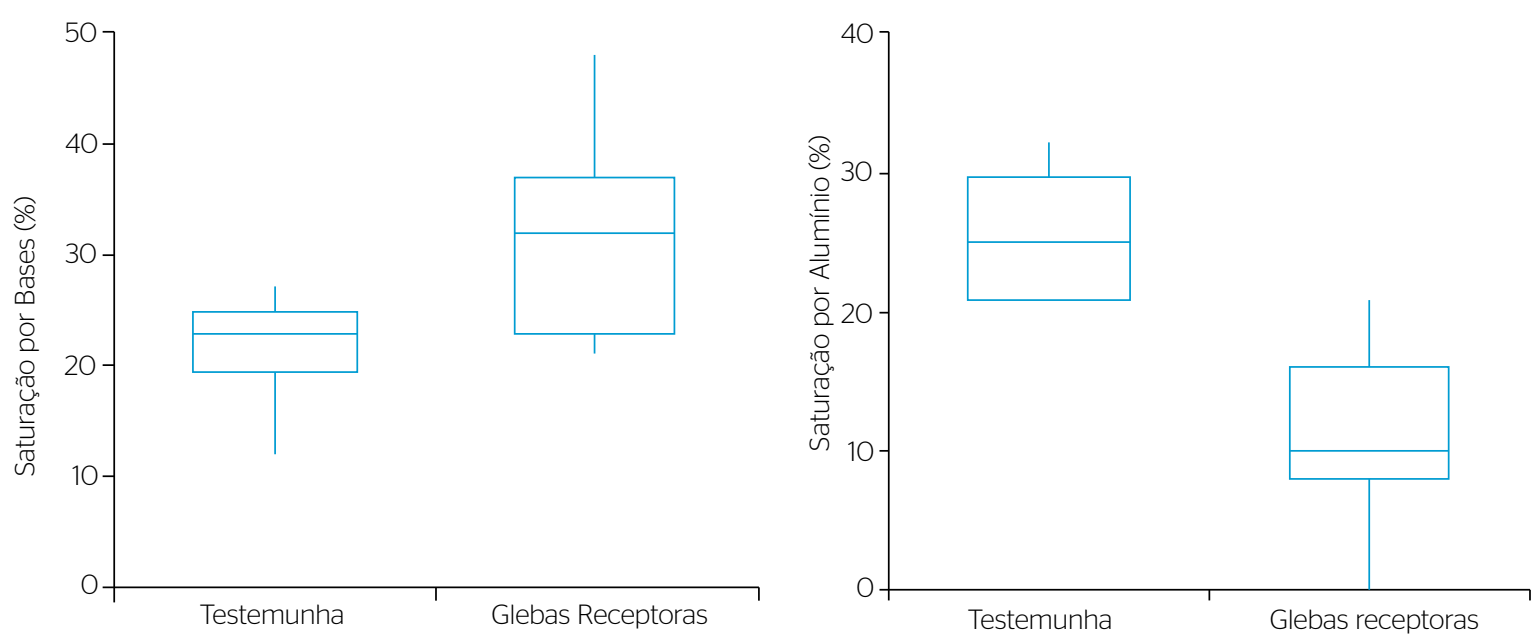

Figura 2 - Box-plot apresentando a mediana, os quartis e o maior e menor valor referente às análises de solo quanto aos parâmetros "Saturação por Bases" e "Saturação por Al" para a gleba testemunha e glebas receptoras de lodo. 
aplicação de 500 t.ha $^{-1}$ de lodo de esgoto em um solo de textura grossa, que o solo tratado com lodo apresentava maiores teores de cálcio e maior CTC do que o solo das parcelas testemunha.

\section{Constituintes inorgânicos no solo}

Para todas as glebas e profundidades do estudo, a concentração de todos os constituintes inorgânicos analisados ( $\mathrm{Co}, \mathrm{Ni}, \mathrm{Cu}, \mathrm{Ba}, \mathrm{Zn}, \mathrm{Al}, \mathrm{B}, \mathrm{Mn}, \mathrm{Fe}, \mathrm{Sb}$, $\mathrm{Cd}, \mathrm{Hg}, \mathrm{Ag}, \mathrm{As}, \mathrm{Mo}, \mathrm{Pb}, \mathrm{Se}$ ) resultou abaixo dos limites máximos referentes aos Valores de Investigação (VI) da Resolução CONAMA n 420/2009 (BRASIL, 2009), os quais apresentam as concentrações de substâncias acima das quais existem riscos diretos ou indiretos para a saúde humana.

Os valores de médias e medianas do solo na profundidade $0-20 \mathrm{~cm}$ da gleba testemunha e glebas receptoras, assim como o valor $\mathrm{p}$ do teste $t$ são apresentados na Tabela 5 . Valores menores que 0,05 para o valor $\mathrm{p}$ foram considerados indicação de diferença significativa entre as médias.

Os resultados dos parâmetros antimônio, cádmio, mercúrio, prata, arsênio, molibdênio, chumbo e selênio não alcançaram o limite de detecção da amostra, portanto não foi possível o cálculo da média, mediana e valor p.

De maneira geral, os valores médios das glebas receptoras resultaram um pouco superiores aos da gleba testemunha, porém não foram verificadas diferenças estatisticamente significativas $(p \leq 0,05)$ na concentração de nenhum constituinte inorgânico no solo entre os tratamentos.

Dessa forma, apesar da tendência de aumento da concentração, os dados indicam que a quantidade aplicada de lodo não causou alteração significativa da concentração dos componentes analisados no solo. Isso é condizente com o fato de o lodo apresentar concentrações baixas desses constituintes, além da quantidade teórica total de cada constituinte inorgânico adicionado ao solo via aplicação de lodo também ser baixa.

Tabela 5 - Média e mediana dos resultados de constituintes inorgânicos no solo, na profundidade $0-20 \mathrm{~cm}$ e valor $\mathrm{p}$ do teste $t$ entre solo receptor e solo testemunha.

\begin{tabular}{|c|c|c|c|c|c|c|}
\hline \multirow[t]{2}{*}{ Parâmetro } & \multirow{2}{*}{ Unidade } & \multicolumn{2}{|c|}{ Testemunha } & \multicolumn{2}{|c|}{$\begin{array}{c}\text { Glebas } \\
\text { receptoras }\end{array}$} & \multirow{2}{*}{$\begin{array}{c}\text { Valor } \\
\mathrm{p}\end{array}$} \\
\hline & & Média & Mediana & Média & Mediana & \\
\hline Cobalto & $\mathrm{mg} \mathrm{kg}^{-1}$ & 8,0 & 8,1 & 9,7 & 7,3 & 0,36 \\
\hline Níquel & mg.kg-1 & 19 & 17 & 29 & 23 & 0,10 \\
\hline Cobre & $\mathrm{mg} \mathrm{kg}^{-1}$ & 27 & 27 & 33 & 33 & 0,25 \\
\hline Bário & mg.kg-1 & 9,8 & 10,9 & 16 & 14 & 0,06 \\
\hline Zinco & mg.kg ${ }^{-1}$ & 18 & 19 & 22 & 21 & 0,20 \\
\hline Alumínio & mg.kg-1 & 81177 & 81373 & 86861 & 92754 & 0,38 \\
\hline Boro & mg.kg-1 & 461 & 395 & 505 & 446 & 0,29 \\
\hline Manganês & mg.kg ${ }^{-1}$ & 202 & 198 & 227 & 215 & 0,29 \\
\hline Ferro & mg.kg ${ }^{-1}$ & 59816 & 59688 & 79691 & 81915 & 0,06 \\
\hline
\end{tabular}

No semestre 3, a gleba 1 ainda não havia recebido nenhum lote de lodo quando o solo foi amostrado, portanto os resultados foram contabilizados na coluna "testemunha".
A qualidade do lodo está diretamente relacionada às características do efluente tratado que o originou (SANEPAR, 1999). No caso do presente estudo, o lodo se originou na ETE de uma indústria alimentícia que não utiliza esses componentes inorgânicos em seu processo produtivo. Assim, é esperado que o lodo gerado contenha concentração baixa dos constituintes inorgânicos estudados, e que a aplicação do resíduo apresente baixo impacto em relação à concentração desses componentes no solo.

Apesar disso, é importante destacar o efeito cumulativo dos constituintes inorgânicos no solo e, por essa razão, é necessário monitoramento periódico dos efeitos da aplicação no ambiente mesmo que a concentração desses constituintes no lodo seja considerada reduzida.

\section{Substâncias orgânicas no solo}

Todos os resultados obtidos referentes às substâncias orgânicas potencialmente tóxicas dos grupos benzenos clorados, ésteres ftálicos, etanos clorados, etenos clorados, fenóis clorados, fenóis não clorados, hidrocarbonetos aromáticos voláteis, hidrocarbonetos policíclicos aromáticos, metanos clorados, PCB e pesticidas organoclorados analisados nas amostras de solo coletadas em todas as glebas do presente estudo encontram-se abaixo dos Valores de Prevenção (VP) da Resolução CONAMA no 420/2009, os quais representam as concentrações de substâncias para as quais o solo seja capaz de sustentar suas funções principais.

Dessa forma, quanto às substâncias orgânicas potencialmente tóxicas analisadas, o solo das glebas 1, 2, 3, 4 e testemunha atendem aos padrões de qualidade determinados na legislação.

Não foi possível a comparação estatística entre os dados da gleba testemunha e das glebas receptoras, uma vez que quase todas as análises resultaram abaixo dos limites de quantificação do laboratório.

\section{CONCLUSÕES}

O lodo utilizado no presente estudo de caso apresenta características compatíveis à aplicação no solo em relação à concentração dos constituintes inorgânicos analisados. Adicionalmente, a aplicação de lodo contribuiu para o aumento da fertilidade do solo das glebas receptoras, indicado pelo aumento da saturação por bases, soma de bases, CTC, matéria orgânica, além da redução do alumínio trocável e da saturação por alumínio.

Foi verificada uma tendência de pequeno aumento da concentração dos constituintes inorgânicos ( $\mathrm{Al}, \mathrm{Ba}, \mathrm{B}, \mathrm{Co}, \mathrm{Cu}, \mathrm{Fe}, \mathrm{Mn}, \mathrm{Ni}, \mathrm{Zn}$ ) no solo receptor de lodo em relação ao solo testemunha, não sendo esse aumento estatisticamente significativo. No entanto, não foi verificado aumento das substâncias orgânicas potencialmente tóxicas no solo da área de aplicação de lodo em relação à testemunha.

Algumas substâncias identificadas no lodo podem apresentar efeito cumulativo no solo, por isso é necessário monitoramento periódico das áreas receptoras do resíduo. 


\section{REFERÊNCIAS}

ASIK, B.B.; AYDINALP, C.; KATKAT, A.V.; SAGBAN, F.O.T. (2O15) Effect of the application of various wastewater sludges on the properties of sandy soil. Environmental Monitoring and Assessment, v. 187, n. 2.

BAGHINA, N.; RADULOV, I; BERBECEA, A.; MOISUC, A.; STROIA, C. (2014) Sewage sludge fertilisation influence on main soil chemical features. Journal of Environmental Protection and Ecology, v. 15, n. 1, p. 217-222.

BETTIOL, W. \& CAMARGO, O.A.A. (2006) Disposição de lodo de esgoto em solo agrícola. In: Lodo de Esgoto: Impactos Ambientais na Agricultura. 1. ed. Jaguariúna: Embrapa Meio Ambiente.

BRASIL. (2006) Conselho Nacional do Meio Ambiente (CONAMA). Resolução no 375, de 29 de agosto de 2006. Define critérios e procedimentos para o uso agrícola de lodos de esgoto gerados em estações de tratamento de esgoto sanitário e seus produtos derivados, e dá outras providências. Diário Oficial da União, Brasília: DF.

BRASIL.(2009) Conselho Nacional do Meio Ambiente (CONAMA). Resolução nO 420, de 28 de dezembro de 2009. Dispõe sobre critérios e valores orientadores de qualidade do solo quanto à presença de substâncias químicas e estabelece diretrizes para o gerenciamento ambiental de áreas contaminadas por essas substâncias em decorrência de atividades antrópicas. Diário Oficial da União, Brasília: DF.

CORREIA, J.R.; REATTO, A.; SPERA, S.T. (2004) Solos e suas relações com o uso e manejo. In: SOUSA, D. M. G. \& LOBATO, E. (Eds.) Cerrado: Correção do solo e adubação. 2. ed. Planaltina: Embrapa. Cap. 13. 346-348p.

DYNIA, J.F.; BOEIRA, R.C.; SOUZA, M.D. (2006) Nitrato no perfil de um latossolo vermelho distroférrico cultivado com milho sob aplicações sequenciais de lodo de esgoto. In: BETTIOL, W. \& CAMARGO, O. (Eds.) Lodo de esgoto: Impactos ambientais na agricultura. 1. ed. Jaguariúna: Embrapa. cap. 5, 79-89p.

HARRISON, R.; XUE, D.; HENRY, C.; COLE, D.W. (1994) Long-term effects of heavy applications of biosolids on organic matter and nutrient content of a coarse-textured forest soil. Forest Ecology and Management, v. 66, p. 165-177.

LARA, A.I.; ANDREOLI, C.V;; PEGORINI, E.S. (2001) Avaliação dos impactos ambientais e monitoramento da disposição final do lodo. In: ANDREOLI, C. V.; SPERLING, M. Von; FERNANDES, F. (Eds.) Lodo de esgotos: Tratamento e disposição final. Belo Horizonte: Departamento de Engenharia Sanitária e Ambiental UFMG, Companhia de Saneamento do Paraná. cap. 11. 465-483p. (Princípios do tratamento biológico de águas residuárias).

LIRA, A.C.S.; GUEDES, M.C.; SCHALCH, V. (2008) Reciclagem de lodo de esgoto em plantação de eucalipto: carbono e nitrogênio. Engenharia Sanitária e Ambiental, v. 13, n. 2, p. 207-216.

LOPES, A.S. (1984) Solos sob cerrado: Características, propriedades e manejo. $2^{a}$ ed. Piracicaba: Associação Brasileira para Pesquisa da Potassa e do Fosfato (POTAFOS). 162 p.
LOPES, A.S. \& GUILHERME, L.R.G. (2004) Interpretação de análise de solo: conceitos e aplicações. São Paulo: Anda - Associação Nacional Para Difusão de Adubos. Boletim Técnico n. 2.

MÉNDEZ-CONTRERAS, J.M.; ATENODORO, J.; CHAMPIÓN, F.A; VALLEJO-CANTÚ, N.A.; ALVARADO-LASSMAN, A. (2009) Inactivation of high concentration of pathogens in land-applied food industry sludge. Water SA, v. 35, n. 4.

MINGORANCE, M.D.; OLIVA, S.R.; VALDÉS, B.; GATA, F.J.P; LEIDI, E.O.; GUZMÁN, I.; PEÑA, A. (2014) Stabilized municipal sewage sludge addition to improve properties of an acid mine soil for plant growth. Journal of Soils and Sediments, v. 14, n. 4, p. 703-712.

NASCIMENTO, C.W.A.; BARROS, D.A.S.; MELO, E.E.C.; OLIVEIRA, A.B. (2004) Alterações químicas em solos e crescimento de milho e feijoeiro após aplicação de lodo de esgoto. Revista Brasileira de Ciência do Solo, v. 28, n. 2, p. 385-392.

NICOLÁS, C; KENNEDY, J.N.; HERNÁNDEZ, T; GARCÍA, C:; SIX, J. (2014) Soil aggregation in a semiarid soil amended with composted and noncomposted sewage sludge - A field experiment. Geoderma, v. 219, p. 24-31.

PAIVA, A.V.; POGGIANI, F.; GONÇALVES, J.L.M.; FERRAZ, A.V. (2OO9) Crescimento de mudas de espécies arbóreas nativas, adubadas com diferentes doses de lodo de esgoto seco e com fertilização mineral. Scientia Forestalis, v. 37, n. 84, p.499-511.

SOUZA, J.C. (2010) Avaliação da suscetibilidade e do potencial a erosão laminar da bacia do ribeirão Sozinha (GO). Dissertação (Mestrado) - Universidade Federal de Goiás, Goiânia.

RAIJ, B; ANDRADE, J.C.; CANTARELLA, H.; QUAGGIO, J.A. (Ed.). (2001) Análise química para avaliação da fertilidade de solos tropicais. Campinas: Instituto Agronômico. 285 p.

SAITO, M.L. (2007) O uso do lodo de esgoto na agricultura: precauções com os contaminantes orgânicos. Jaguariúna: Embrapa.

SANEPAR - Companhia de Saneamento do Paraná. (1999) Uso e manejo do lodo de esgoto na agricultura. Curitiba (PR), Brasil.

SILVA, S.M.C.P; FERNANDES, F.; SOCCOL, V.T.; MORITA, D.M. Principais contaminantes do lodo. In: ANDREOLI, C.V.; SPERLING, M.; FERNANDES, F. (Eds.). (2001) Lodo de esgotos: Tratamento e disposição final. Belo Horizonte: Departamento de Engenharia Sanitária e Ambiental - UFMG, Companhia de Saneamento do Paraná. Cap. 3. 69-122p. (Princípios do tratamento biológico de águas residuárias).

SILVA, C.A.; RANGEL, O.J.P; BETTIOL, W.; MANZATTO, C.V.; BOEIRA, R.C.; DYNIA, J.F. Dinâmica de metais pesados em latossolo adubado com lodo de esgoto e em plantas de milho. In: BETTIOL, W. \& CAMARGO, O. (Eds.). (2006) Lodo de esgoto: Impactos ambientais na agricultura. $1^{a}$ ed. Jaguariúna: Embrapa. cap. 4, 45-77p.

SILVA, P.H.M.; POGGIANI, F.; GONÇALVES, J.L.M.; STAPE, J.L.; MOREIRA, R.M. (2008) Crescimento de Eucalyptus grandis tratado com diferentes doses de lodos de esgoto úmido e seco, condicionados com polímeros. Scientia Forestalis, v. 36, n. 77, p. 79-88. 
SMITH,S. (2009) Organic contaminants in sewage sludge(biosolids) and their significance for agricultural recycling. Philosophical Transactions of the Royal Society, v. 367, n. 1904, p. 4005-4041.

UNAL, M. \& KATKAT, A.V. (2009) The effects of food industry sludge on soil properties and growing of maize (Zea mays L.). Journal of Food Agriculture \& Environment, v. 7, n. 2, p. 435-440.

USEPA - UNITED STATES ENVIRONMENTAL PROTECTION AGENCY (1989). Method 505: Analysis of organohalide pesticides and commercial polychlorinated biphenyl (PCB) products in water by microextraction and gas chromatography. Washington: USEPA.

USEPA - UNITED STATES ENVIRONMENTAL PROTECTION AGENCY (1994). Method 1613: Tetra- through octa-chlorinated dioxins and furans by isotope dilution HRGC/HRMS. Washington: USEPA.

USEPA - UNITED STATES ENVIRONMENTAL PROTECTION AGENCY (1996). Method 8260C: Volatile organic compounds by gas chromatography/ mass spectrometry. Test methods for evaluating solid waste, physical/chemical methods (SW846). Washington: USEPA.
USEPA - UNITED STATES ENVIRONMENTAL PROTECTION AGENCY (2004). Method 9045D: Soil and waste pH. Test methods for evaluating solid waste, physical/chemical methods (SW846). Washington: USEPA.

USEPA - UNITED STATES ENVIRONMENTAL PROTECTION AGENCY (2005). Method 245.7: Mercury in water by cold vapor atomic fluorescence spectrometry. Washington: USEPA.

USEPA - UNITED STATES ENVIRONMENTAL PROTECTION AGENCY (2007a). Method 6010: Inductively coupled plasmaatomic emission spectrometry. Test methods for evaluating solid waste, physical/chemical methods (SW846). Washington: USEPA.

USEPA - UNITED STATES ENVIRONMENTAL PROTECTION AGENCY (2007b). Method 3051: Microwave assisted acid digestion of sediments, sludges, soils and oil. Test methods for evaluating solid waste, physical/chemical methods (SW846). Washington: USEPA.

USEPA - UNITED STATES ENVIRONMENTAL PROTECTION AGENCY (2007c). Method 8270D: Semivolatile organic compounds by gas chromatography/mass spectrometry. Test methods for evaluating solid waste, physical/chemical methods (SW846). Washington: USEPA. 